А. В. Шободоева

Байкальский государственный университет, г. Иркутск, Российская Федерация

C. А. Чмара

Байкальский государственный университет, 2. Иркутск, Российккая Федерация

А. А. Преловский

Байкальский государственный университет, г. Иркутск, Российская Федерация

\title{
НАЦИОНАЛЬНЫЕ ИНТЕРЕСЫ РОССИЙСКОЙ ФЕДЕРАЦИИ В ИНФОРМАЦИОННОЙ СФЕРЕ
}

\begin{abstract}
АНнОтАЦия. Современный этап развития государства и общества демонстрирует увеличивающееся значение информационной сферы, которая является основанием большего числа составляющих национальной безопасности нашей страны. Процессы глобализации, объективно связанные с трансформацией миропорядка в современное время, ставят новые проблемы, требуют новых подходов в определении национальных интересов и приоритетов в информационной сфере. Подобные интересы, несомненно, носят долгосрочный характер и определяют основные цели, стратегические и текущие задачи информационной политики нашего государства. Но, при этом, они требуют их своевременной корректировки, так как приоритеты современного независимого развития России в значительной степени зависят от того, насколько четко и недвусмысленно сформулированы интересы в информационной сфере. Анализ современных нормативно-правовых источников и литературы свидетельствует об отсутствии единого понимания категории «национальный интерес в информационной сфере». В статье не только представлен данный процесс, но и проведен сравнительный анализ национальных интересов России в информационной сфере в Доктрине информационной безопасности 2000 года и новом документа, принятом в 2016 г.

кЛючЕВЫЕ словА. Информационная безопасность; национальные интересы РФ; национальные интересы РФ в сфере информационной безопасности.

ИНФОРМАЦИЯ О СТАТЬЕ. Дата поступления 23 января 2017 г.; дата принятия к печати 2 февраля 2017 г.; дата онлайн-размещения 31 марта 2017 г.
\end{abstract}

A. V. Shobodoyeva Baikal State University, Irkutsk, Russian Federation

S. A. Chmara

Baikal State University, Irkutsk, Russian Federation

A. A. Prelovsky Baikal State University, Irkutsk, Russian Federation

\section{NATIONAL INTERESTS OF THE RUSSIAN FEDERATION IN INFORMATION SPHERE}

ABSTRACT. The present-day development stage for the state and society demonstrates an increased significance of the information sphere which appears to be the basis of a great number of constituents of our country's national security. The globalization processes, connected objectively with the world order transformation in our modern

(C) А. В. Шободоева, С. А. Члмара, А. А. Преловский, 2017

\section{Baikal Research Journal}

электронный научный журнал Байкальского государственного университета 
days, bring forth new problems, demand new approaches to identifying national interests and priorities in the information sphere. Such interests have a long-term character and determined main objectives, strategic and current tasks of our state's information policy. But along with that, they demand their well-timed correction as the priorities of Russia's modern independent development depend significantly on how distinctly and explicitly the interests in the information sphere have been formulated. An analysis of the current-day statuary sources and literature testifies an absence of uniform understanding of the category "national interest in the information sphere». The article not only presents this process but also carries out a comparative analysis of Russia's national interests in the information sphere in the 2000 Doctrine of Information Security and in a new document adopted in 2016.

KEYWORDS. Information security; RF national interests; $\mathrm{RF}$ national interests in information security sphere.

ARTICLE INFO. Received January 23, 2017; accepted February 2, 2017; available online March 31, 2017.

Конец XX и начало XXI в. характеризуются новым этапом научно-технической революции, связанным с проникновением во все сферы жизни информационно-коммуникационных технологий, которые формируют основу для перехода к информационному обществу.

Исследователи делают вывод о смене индустриального типа общества на качественно новый тип - информационный $[1$, с. 818; 2, с. 728; 3, с. 26-27].

Этот факт со всей очевидностью зафиксирован и в Стратегии развития информационного общества в Российской Федерации ${ }^{1}$.

Отличие информационного общества от других социальных организаций заключается в том, что оно выступает как связь информационной среды между человеком и общественными институтами. Информационное общество формируется в результате информационной революции. Последняя означает широкое развитие новых информационных систем и создание новых информационных технологий. Информационную революцию также создало информационное общество. Это такое общество, где национальные границы теряют свое значение, а национальные взаимоотношения и традиции объединяются в единую информационную организацию [4, с. 117].

И в данных условиях особую роль играет обеспечение информационной безопасности Российской Федерации. Под информационной безопасностью Российской Федерации понимается состояние защищенности личности, общества и государства от внутренних и внешних информационных угроз, при котором обеспечиваются реализация конституционных прав и свобод человека и гражданина, достойные качество и уровень жизни граждан, суверенитет, территориальная целостность и устойчивое социально-экономическое развитие Российской Федерации, оборона и безопасность государства (п. 2 «в $)^{2}$.

Приведенное определение представлено в тексте новой Доктрины информационной безопасности РФ, подписанной Президентом В. В. Путиным 5 декабря 2016 г. Предыдущая Доктрина информационной безопасности была датирована 2000 г. $^{3}$, и в ней информационная безопасность Российской Федерации — это состояние защищенности ее национальных интересов в информационной сфере,

1 Стратегия развития информационного общества в Российской Федерации [Электронный ресурс] : утв. Президентом РФ 7 февр. 2008 г. № Пр-212 // СПС «КонсультантПлюс».

${ }^{2}$ Об утверждении Доктрины информационной безопасности Российской Федерации : указ Президента РФ от 5 дек. 2016 г. № 646 // Собрание законодательства РФ. 2016. № 50. Ст. 7074.

${ }^{3}$ Доктрина информационной безопасности Российской Федерации [Электронный ресурс] : утв. Президентом РФ 9 сент. 2000 г. № Пр-1895 // СПС «КонсультантПлюс».

\section{Baikal Research Journal}


определяющихся совокупностью сбалансированных интересов личности, общества и государства.

Само понятие «информационная безопасность», таким образом, невозможно без понимания того, как законодатель представляет национальные интересы в сфере информационной безопасности России, так как и нормативно-правовая база, и ее доктринальное толкование связывают категорию «информационная безопасность» с защитой прав и свобод человека и гражданина и национальных интересов РФ [3-9].

Рассмотреть данный вопрос необходимо при опоре на сравнение основных положений Доктрин информационной безопасности РФ.

Доктрина информационной безопасности Российской Федерации 2016 года представляет собой систему официальных взглядов на обеспечение национальной безопасности Российской Федерации в информационной сфере. Под информационной сферой в Доктрине понимается совокупность информации, объектов информатизации, информационных систем, сайтов в информационно-телекоммуникационной сети «Интернет», сетей связи, информационных технологий, субъектов, деятельность которых связана с формированием и обработкой информации, развитием и использованием названных технологий, обеспечением информационной безопасности, а также совокупность механизмов регулирования соответствующих общественных отношений (п. 1).

В Доктрине же информационной безопасности 2000 года отмечалось, что, не являясь нормативно-правовым актом, она нацелена на:

- формирование государственной политики в области обеспечения информационной безопасности Российской Федерации;

- подготовку предложений по совершенствованию правового, методического, научно - технического и организационного обеспечения информационной безопасности Российской Федерации;

- разработку целевых программ обеспечения информационной безопасности Российской Федерации (Преамбула).

И в первом разделе данной Доктрины рассматривалось состояние информационной безопасности и основные задачи по ее обеспечению в нашей стране, формулировались национальные интересы РФ в информационной сфере и их обеспечение, классифицировались виды угроз информационной безопасности и их источники, как внешние, так и внутренние.

Доктрина:

- определяла системообразующий характер информационной сферы, подчеркивала ее значительное влияние на состояние политической, экономической, оборонной и других составляющих безопасности Российской Федерации;

- формулировала ряд основных понятий в сфере информационной безопасности и устанавливала национальные приоритеты Российской Федерации в данной области;

- вычленяла основные принципы, направления и задачи государственной политики обеспечения информационной безопасности Российской Федерации;

- фиксировала, что важнейшей задачей государства в области информационной безопасности должно являться обеспечение гарантий конституционных прав и свобод человека и гражданина на доступ к информации и обеспечение полноценных возможностей для деятельности в информационной сфере;

- устанавливала, что государственные информационные ресурсы - это важнейшие объекты обеспечения безопасности страны;

- отмечала необходимость баланса интересов личности, общества и государства в данном вопросе, обозначала проблематику по каждому перечисленному

\section{Baikal Research Journal}


выше субъекту и пути ее разрешения. Но приоритетным направлением признавалось обеспечение информационной безопасности именно государства. Но, тем не менее, значительное внимание уделяется информационно-психологическому направлению политики обеспечения национальной безопасности, реализации роли человеческого фактора в этом процессе.

Но к современному периоду времени ряд положений Доктрины уже объективно не отвечали потребностям обеспечения информационной безопасности РФ.

Во-первых, Доктрина развивала и детализировала «Концепцию национальной безопасности Российской Федерации» применительно к информационной сфере. Но данный документ был принят в 1997 г. (редакция 2000 г.). Ему на смену в 2009 г. пришла Стратегия национальной безопасности РФ до 2020 года, которую заменила Стратегия национальной безопасности РФ 2015 года. Соответственно, правовая основа Доктрины кардинально устарела.

Во-вторых, Доктрина слабо стыковалась с положениями других концептуальных актов в данной сфере, в частности, со Стратегией развития информационного общества в Российской Федерации 2008 года, Концепцией региональной информатизации 2014 года ${ }^{4}$, Концепцией информационной безопасности детей 2015 года ${ }^{5}$ и др.

В-третьих, устарели формулировки как интересов РФ в информационной сфере, так и внутренние и внешние угрозы и их источники. Принципиальной корректировки, в соответствии с изменившейся международной и внутриполитической ситуацией, требуют национальные приоритеты в информационной области и возникающие вызовы, опасности и угрозы в данной сфере.

Эти (и ряд других) причин предопределили разработку новой Доктрины информационной безопасности РФ, текст которой в июне 2016 г. был опубликован Советом Безопасности $\Phi^{6}$ для обсуждения, а в декабре 2016 года введен в действие.

Начнем с понятия «национальные интересы России в информационной сфеpe». Не останавливаясь на многочисленных вариантах, представляемых российскими учеными, мы предлагаем сразу обратиться к положению Доктрины информационной безопасности Российской Федерации 2016 года. Исходя из данного документа, национальные интересы Российской Федерации в информационной сфере - это объективно значимые потребности личности, общества и государства в обеспечении их защищенности и устойчивого развития в части, касающейся информационной сферы (2 «а»).

Это соотносится с нормативным объяснением категории «национальный интерес» в Стратегии национальной безопасности РФ 2015 года (п. 6). Анализ приведенного определения позволяет объяснить логику отсутствия в новой Доктрине 2016 года отдельных положений об интересах личности, общества и государства в информационной сфере. В Доктрине информационной безопасности 2000 года они выглядели следующим образом:

- интересы личности в информационной сфере заключаются в реализации конституционных прав человека и гражданина на доступ к информации, на использование информации в интересах осуществления не запрещенной законом

${ }^{4}$ Об утверждении Концепции региональной информатизации : распоряжение Правительства РФ от 29 дек. 2014 г. № 2769-р // Собрание законодательства РФ. 2015. № 2. Ст. 544.

${ }^{5}$ Об утверждении Концепции информационной безопасности детей : распоряжение Правительства РФ от 2 дек. 2015 г. № 2471-р //Там же. № 49. Ст. 7055.

${ }^{6}$ Доктрина информационной безопасности Российской Федерации (проект) [Электронный реcypc]. URL: http://www.scrf.gov.ru/documents/6/135.html.

\section{Baikal Research Journal}


деятельности, физического, духовного и интеллектуального развития, а также в защите информации, обеспечивающей личную безопасность;

- интересы общества в информационной сфере заключаются в обеспечении интересов личности в этой сфере, упрочении демократии, создании правового социального государства, достижении и поддержании общественного согласия, в духовном обновлении России;

- интересы государства в информационной сфере заключаются в создании условий для гармоничного развития российской информационной инфраструктуры, для реализации конституционных прав и свобод человека и гражданина в области получения информации и пользования ею в целях обеспечения незыблемости конституционного строя, суверенитета и территориальной целостности России, политической, экономической и социальной стабильности, в безусловном обеспечении законности и правопорядка, развитии равноправного и взаимовыгодного международного сотрудничества (п. 1).

И хотя собственно сущность термина «национальные интересы в информационной сфере» в указанной Доктрине 2000 года не закреплялась, можно было понять, что под ними подразумевалась совокупность интересов государства, общества и личности. Национальные интересы в информационной сфере определяются, прежде всего, той ролью, которую в современном мире играет информация, информационная инфраструктура. И хочется еще раз подчеркнуть основную мысль первого раздела Доктрины информационной безопасности 2000 года - сбалансированная совокупность интересов личности, общества и государства, реализуемая в информационной сфере, и отражает сущность национальных интересов. Соответственно, в новой Доктрине информационной безопасности РФ 2016 года предлагается термин «национальные интересы», что поглощает понятия интересы личности, общества и государства.

Рассмотрим, как законодатель формулирует интересы России в информационной сфере и их изменение за 16 лет (табл.).

Анализ национальных интересов в сфере информационной безопасности позволяет разделить их на две группы.

Здесь следует сделать важное теоретическое отступление. Известные исследователи проблем национальной безопасности вообще, и, информационной, в частности (доктор философских наук, профессор Э. Н. Камышев, доктор философских наук профессор А. И. Поздняков, доктор политических наук, профессор И. Н. Панарин и др.), предлагали выделять две стороны информационной безопасности: информационно-психологическую и информационно-техническую [10-12].

Первая связана с возможностью интенсивного влияния на интеллектуальный, духовный и психологический потенциал общества. В данном случае основными объектами защиты являются психика всех категорий населения страны, а также системы формирования общественного сознания, мнения и принятия решений.

Вторая составляющая связана с безопасным функционированием и развитием информационной инфраструктуры государства, информационной промышленности и производства технологий. Здесь главные объекты защиты - системы связи и телекоммуникаций, радиоэлектронные средства и т. д.

Естественно, в жизни эти стороны находятся в тесной взаимосвязи и взаимозависимости.

В Доктрине информационной безопасности 2000 года первая группа интересов - это два первых интереса, которые отображают информационно-психологическую безопасность, вторая группа - третий и четвертый интерес - информационно-техническую.

\section{Baikal Research Journal}

электронный научный журнал Байкальского государственного университета 


\section{Национальные интересы РФ в инфорлационной сфере}

\begin{tabular}{|c|c|}
\hline $\begin{array}{c}\text { Доктрина информационной безопасности } \\
\text { Российской Федерации } 2000 \text { года }\end{array}$ & $\begin{array}{c}\text { Доктрина информационной безопасности } \\
\text { Российской Федерации } 2016 \text { года }\end{array}$ \\
\hline $\begin{array}{l}\text { Соблюдение конституционных прав и } \\
\text { свобод человека и гражданина в области } \\
\text { получения информации и пользования } \\
\text { ею, обеспечение духовного обновления } \\
\text { России, сохранение и укрепление нрав- } \\
\text { ственных ценностей общества, традиций } \\
\text { патриотизма и гуманизма, культурного и } \\
\text { научного потенциала страны (1). } \\
\text { Информационное обеспечение государ- } \\
\text { ственной политики Российской Федера- } \\
\text { ции, связанное с доведением до россий- } \\
\text { ской и международной общественности } \\
\text { достоверной информации о государствен- } \\
\text { ной политике Российской Федерации, ее } \\
\text { официальной позиции по социально зна- } \\
\text { чимым событиям российской и между- } \\
\text { народной жизни, с обеспечением доступа } \\
\text { граждан к открытым государственным } \\
\text { информационным ресурсам (2). } \\
\text { Развитие современных информаци- } \\
\text { онных технологий, отечественной инду- } \\
\text { стрии информации, в том числе индустрии } \\
\text { средств информатизации, телекоммуника- } \\
\text { ции и связи, обеспечение потребностей } \\
\text { внутреннего рынка ее продукцией и вы- } \\
\text { ход этой продукции на мировой рынок, а } \\
\text { также обеспечение накопления, сохранно- } \\
\text { сти и эффективного использования отече- } \\
\text { ственных информационных ресурсов (3). } \\
\text { Защиту информационных ресурсов от } \\
\text { несанкционированного доступа, обеспе- } \\
\text { чение безопасности информационных и } \\
\text { телекоммуникационных систем, как уже } \\
\text { развернутых, так и создаваемых на терри- } \\
\text { тории России (4) (п. 1) }\end{array}$ & 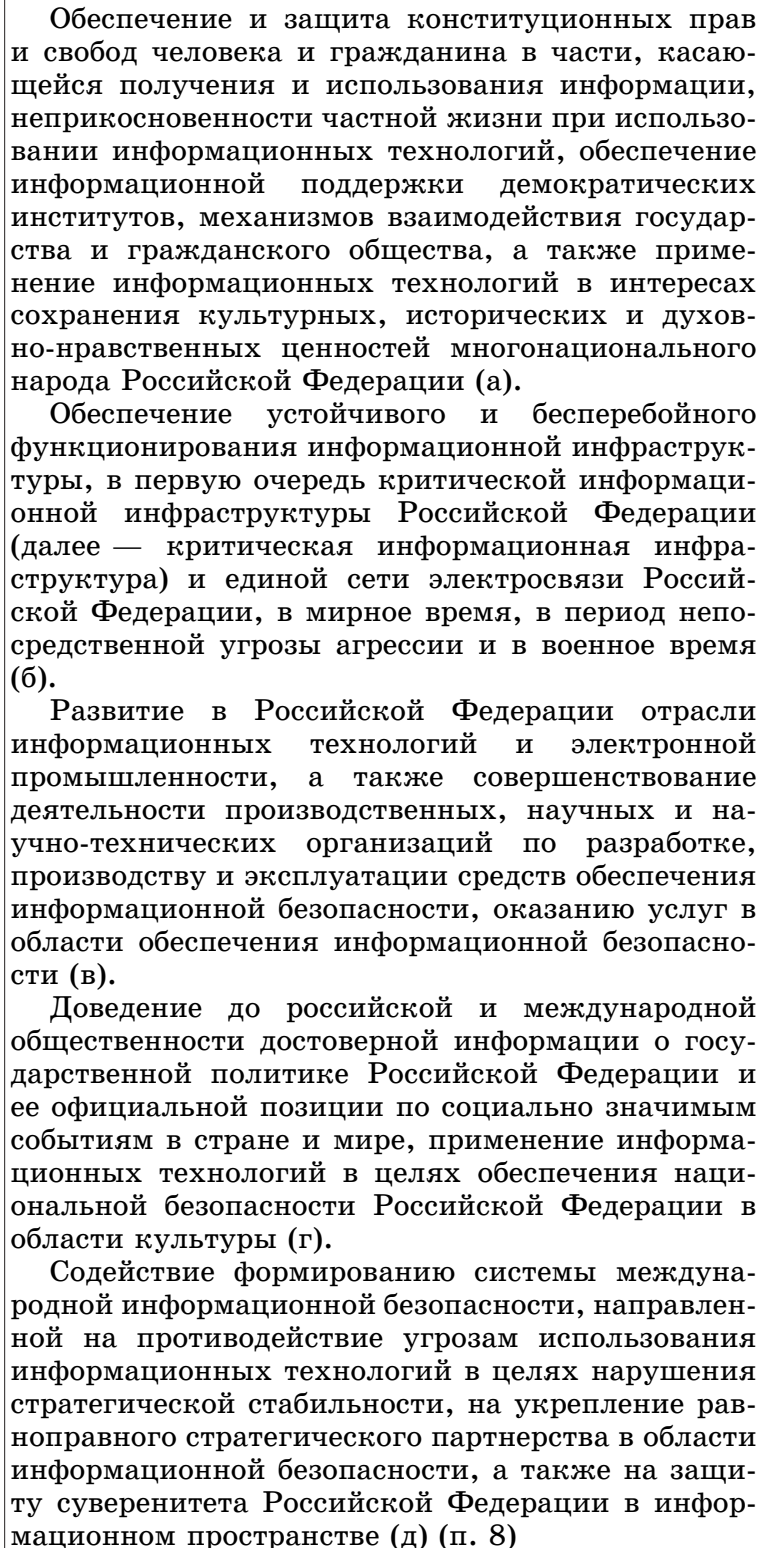 \\
\hline
\end{tabular}

Законодатель, как следует из проекта новой Доктрины информационной безопасности 2016 года, расширяет, уточняет и конкретизирует свои национальные интересы в информационной сфере. Обращаем внимание на следующие базовые моменты:

1. Количество национальных интересов в информационной сфере увеличено. Информационно-психологическая безопасность в проекте новой Доктрины связана, на наш взгляд, с учетом трех национальных интересов (a, г, д), а информационно-техническая - двух (б, в).

\section{Baikal Research Journal}


2. Реализация национальных интересов в информационной сфере направлена на формирование безопасной среды оборота достоверной информации и устойчивой к различным видам воздействия информационной инфраструктуры в целях обеспечения конституционных прав и свобод человека и гражданина, стабильного социально-экономического развития страны, а также национальной безопасности Российской Федерации (п. 9).

3. Особое внимание стали уделять гуманитарному аспекту информационной безопасности. Упор делается именно на сохранение культурных, исторических и духовно-нравственных ценностей многонационального народа Российской Федерации. Данное внимание объясняется тем, что наращивается негативное информационное воздействие на население России, в первую очередь на молодежь, с целью размывания культурных и духовных ценностей, подрыва нравственных устоев, исторических основ и патриотических традиций нашего народа.

К сожалению, в наибольшей степени воздействию информационной среды подвержена именно духовная сфера общества, деформация которой влияет на состояние и процессы во всех основных сферах общественной жизни России. Законодатель прекрасно понимает, что современный этап развития не снижает, а, наоборот, усиливает стремление деструктивных элементов к использованию новейших технологий информационного воздействия для манипуляции общественным мнением, дезориентации населения страны, фальсификации ситуации в социально-экономической, общественно-политической, культурно-духовной, морально-психологической и других сферах.

4. В рамках реализации национальных интересов РФ в информационной сфере новая Доктрина отмечает насущную потребность расширения международного сотрудничества. Подчеркивается, что разъяснению объективной и достоверной информации о государственной политике Российской Федерации, об официальной позиции ее высшего политического руководства по социально значимым событиям в стране и мире, о необходимости укрепления равноправного стратегического партнерства в области информационной безопасности, обеспечения суверенитета Российской Федерации в информационном пространстве противодействует политика ряда зарубежных стран. Акцентируется внимание на стремлении заполнить средства массовой информации зарубежных стран данными, не соответствующими описанию подлинного положения дел в нашей стране. Российским журналистам за рубежом создаются препятствия для осуществления их профессиональной деятельности. Нагнетается межнациональная напряженность, разжигается этническая и религиозная ненависть или вражда.

Для нейтрализации подобных явлений представители РФ стараются принимать участие в важнейших международных программах. Эти программы разрабатываются и обсуждаются на уровне Международных межправительственных организаций, Международных неправительственных организаций и т. п. Их цель - донесение до российской и международной общественности правдивой информации, формирование такого международного режима, который не позволит использовать информационные технологии для нарушения стратегической стабильности.

Подводя итог, отметим:

- смыслом обеспечения национальных интересов в информационной сфере является достижение должного уровня информационной безопасности Российской Федерации, обеспечивающего защищенность и возможность развития личности, общества и государства в указанной области;

- национальные интересы Российской Федерации в информационной сфере носят долгосрочный характер. Они предопределяют основные цели развития не только информационной безопасности, но, в целом, и национальной безопасности РФ;

\section{Baikal Research Journal}

электронный научный журнал Байкальского государственного университета 
- рассматриваемые интересы корреспондируются с национальными интересами и стратегическими национальными приоритетами Российской Федерации, представленными в Стратегии национальной безопасности Российской Федерации 2015 года;

- приоритеты национальных интересов в информационной области не статичны, они изменяются вместе с трансформацией внутренних и внешних обстоятельств и, соответственно, защита интересов от возникающих негативных факторов создает основу деятельности по обеспечению информационной безопасности Российской Федерации.

\section{Список использованной литературы}

1. Архипова 3. В. Трансформация «электронного правительства» в «цифровое правительство» / 3. В. Архипова // Известия Байкальского государственного университета. 2016. - T. 26, № 5. - C. 818-824. - DOI: 10.17150/2500-2759.2016.26(5).818-824.

2. Гонежук 3. Н. Основные направления совершенствования законодательства Российской Федерации в информационной сфере / 3. Н. Гонежук // Научный журнал Кубанского государственного аграрного университета. — 2015. — № 114. - С. 727-736.

3. Данилов А. П. К вопросу об информационной безопасности в регионах Российской Федерации: историко-правовые аспекты / А. П. Данилов, А. А. Данилов // Вестник Чувашского университета. - 2015. - № 2. - С. 26-30.

4. Маммедярова Р. А. Проблемы информационной безопасности в условиях глобализации / Р. А. Маммедярова // Вестник Национального университета «Юридическая академия Украины им. Ярослава Мудрого». Сер.: Философия, философия права, политология, социология. - 2014. - № 1 (20). - С. 116-120.

5. Киселев А. К. Актуальные проблемы обеспечения защиты информации правовыми средствами / А. К. Киселев // Юридическая наука. - 2014. - № 3. - С. 63-66.

6. Лопатин Ю. Н. Информационная безопасность в России. Проблемы, поиски решений / Ю. Н. Лопатин // Гуманитарные исследования в Восточной Сибири и на Дальнем Востоке. - 2008. - № 2. - С. 51-57.

7. Мазуров В. А. Понятие и принципы информационной безопасности / В. А. Мазуров, В. В. Невинский // Известия Алтайского государственного университета. - 2003. № 2. - С. 57-63.

8. Шамсуев М. Х. Теоретические аспекты изучения информационной безопасности / М. Х. Шамсуев // Теория и практика общественного развития. - 2010. — № 2. - С. 319-325.

9. Шевко Н. Р. Актуальные проблемы обеспечения информационной безопасности современного общества / Н. Р. Шевко // Вестник Казанского юридического института МВД России. - 2012. - № 8. - С. 57-59.

10. Камышев Э. Н. Информационная безопасность и защита информации : учеб. пособие / Э. Н. Камышев. - Томск : Изд-во Том. политехн. ун-та, 2009. - 95 с.

11. Тонконогов А. В. Информационно-психологическая безопасность в системе духовной безопасности современной России / А. В. Тонконогов // Власть. - 2010. - № 6. - С. 53-56.

12. Панарин И. Н. Коммуникационный суверенитет России [Электронный ресурс] И. Н. Панарин. - Режим доступа: http://нцпти.pф/materialy-ntspti/?ELEMENT_ID=155.

\section{References}

1. Arkhipova Z. V. Transformation of «The Electronic Government» into «The Digital Government». Izvestiya Baykal'skogo gosudarstvennogo universiteta = Bulletin of Baikal State University, 2016, vol. 26, no. 5, pp. 818-824. DOI: 10.17150/2500-2759.2016.26(5).818-824. (In Russian).

2. Gonezhuk Z. N. Basic directions of mastering legislation of the Russian Federation in the information sphere. Nauchnyi zhurnal Kubanskogo gosudarstvennogo agrarnogo universiteta $=$ Scientific Journal of Kuban State Agrarian University, 2015, no. 114, pp. 727-736. (In Russian).

3. Danilov A. P., Danilov A. A. On issue of information security in regions of the Russian Federation: historical and legal aspects. Vestnik Chuvashskogo universiteta = Bulletin of Chuvash State University, 2015, no. 2, pp. 26-30. (In Russian).

\section{Baikal Research Journal}

электронный научный журнал Байкальского государственного университета 
4. Mammedyarova R. A. Problems of information security in the context of globalization. Vestnik Natsional'nogo universiteta "Yuridicheskaya akademiya Ukrainy im. Yaroslava Mudrogo». Seriya: Filosofiya, filosofiya prava, politologiya, sotsiologiya = Journal of National University "Yaroslav the Wise Law Academy of Ukraine». Series: Philosophy, Philosophy of Law, Political Science, Sociology, 2014, no. 1 (20), pp. 116-120. (In Russian).

5. Kiselev A. K. Topical problems of providing information protection by legal means. Yuridicheskaya nauka = Juridical Science, 2014, no. 3, pp. 63-66. (In Russian).

6. Lopatin Yu. N. Information security in Russia. Problems, search for solutions. Gumanitarnye issledovaniya $v$ Vostochnoi Sibiri i na Dal'nem Vostoke = Humanities Research in East Siberia and the Far East, 2008, no. 2, pp. 51-57. (In Russian).

7. Mazurov V. A., Nevinsky V. V. Concept and principles of information security. Izvestiya Altayskogo gosudarstvennogo universiteta. = Bulletin of Altai State University, 2003, no. 2, pp. 57-63. (In Russian).

8. Shamsuyev M. Kh. Theoretical aspects of studying information security. Teoriya i praktika obshchestvennogo razvitiya $=$ Theory and Practice of Social Development, 2010, no. 2, pp. 319-325. (In Russian).

9. Shevko N. R. Topical problems of providing information security of modern society. Vestnik Kazanskogo yuridicheskogo instituta MVD Rossii = Bulletin of Kazan Law Institute of Russian Ministry of Interior Affairs, 2012, no. 8, pp. 57-59. (In Russian).

10. Kamyshev E. N. Informatsionnaya bezopasnost' $i$ zashchita informatsii [Information security and information protection]. Tomsk Polytechnical University Publ., 2009. 95 p.

11. Tonkonogov A. V. Information and psychological security in the system of spiritual security of modern Russia. Vlast' = The Power, 2010, no. 6, pp. 53-56. (In Russian).

12. Panarin I. N. Kommunikatsionnyi suverenitet Rossii [Communication Sovereignty of Russia]. Available at: http://нцпти.pф/materialy-ntspti/?ELEMENT_ID=155. (In Russian).

\section{Информация об авторах}

Шободоева Анна Владилировна - кандидат исторических наук, магистр юриспруденции, доцент, кафедра правового обеспечения национальной безопасности, Байкальский государственный университет, 664003, г. Иркутск, ул. Ленина, 11, e-mail: sav_irk@mail.ru.

Члара Сергей Анатольевич - старший преподаватель, кафедра правового обеспечения национальной безопасности, Байкальский государственный университет, 664003, г. Иркутск, ул. Ленина, 11, e-mail: chmarasa@bgu.ru.

Преловский Александр Александрович - старший преподаватель, кафедра правового обеспечения национальной безопасности, Байкальский государственный университет, 664003, г. Иркутск, ул. Ленина, 11, e-mail: PrelovskyAA@bgu.ru.

\section{Authors}

Anna V. Shobodoyeva - PhD in History, Master of Jurisprudence, Associate Professor, Chair of Legal Provision of National Security, Baikal State University, 11 Lenin St., 664003, Irkutsk, Russian Federation; e-mail: sav_irk@mail.ru.

Sergey A. Chmara - Senior Lecturer, Chair of Legal Provision of National Security, Baikal State University, 11 Lenin St., 664003, Irkutsk, Russian Federation; e-mail: chmarasa@bgu.ru.

Aleksandr A. Prelovsky - Senior Lecturer, Chair of Legal Provision of National Security, Baikal State University, 11 Lenin St., 664003, Irkutsk, Russian Federation; e-mail: PrelovskyAA@bgu.ru.

\section{Библиографическое описание статьи}

Шободоева А. В. Национальные интересы Российской Федерации в информационной сфере / А. В. Шободоева, С. А. Чмара, А. А. Преловский // Baikal Research Journal. 2017. - T. 8, № 1. — DOI: 10.17150/2411-6262.2017.8(1).24.

\section{Reference to article}

Shobodoyeva A. V., Chmara S. A., Prelovsky A. A. National interests of the Russian Federation in information sphere. Baikal Research Journal, 2017, vol. 8, no. 1. DOI: 10.17150/24116262.2017.8(1).24. (In Russian).

\section{Baikal Research Journal}

